\title{
Chronic fatigue syndrome in an ethnically diverse population: the influence of psychosocial adversity and physical inactivity
}

\author{
Kamaldeep S Bhui ${ }^{1 * \dagger}$, Sokratis Dinos ${ }^{1 \dagger}$, Deborah Ashby ${ }^{2 \dagger}$, James Nazroo ${ }^{3 \dagger}$, Simon Wessely ${ }^{4 \dagger}$ and Peter D White ${ }^{1+}$
}

\begin{abstract}
Background: Chronic fatigue syndrome (CFS) is a complex multifactorial disorder. This paper reports the prevalence of chronic fatigue (CF) and CFS in an ethnically diverse population sample and tests whether prevalence varies by social adversity, social support, physical inactivity, anxiety and depression.

Methods: Analysis of survey data linking the Health Survey for England (1998 and 1999) and the Ethnic Minority Psychiatric Illness Rates in the Community (EMPIRIC) study undertaken in 2000. The study population comprised a national population sample of 4,281 people ages 16 to 74 years. CF and CFS were operationally defined on the basis of an interview in the EMPIRIC study, alongside questions about psychosocial risk factors. Previous illnesses were reported in the Health Survey for England during 1998 and 1999, as was physical inactivity.
\end{abstract}

Results: All ethnic minority groups had a higher prevalence of CFS than the White group. The lowest prevalence was $0.8 \%$ in the White group, and it was highest at 3.5\% in the Pakistani group (odds ratio (OR), 4.1; $95 \%$ confidence interval $(95 \% \mathrm{Cl}), 1.6$ to 10.4). Anxiety $(\mathrm{OR}, 1.8 ; 95 \% \mathrm{Cl}, 1.4$ to 2.2$)$, depression $(\mathrm{OR}, 1.4 ; 95 \% \mathrm{Cl}, 1.1$ to 1.8$)$, physical inactivity $(\mathrm{OR}, 2.0 ; 95 \% \mathrm{Cl}, 1.1$ to 3.8$)$, social strain $(\mathrm{OR}, 1.24 ; 95 \% \mathrm{Cl}, 1.04$ to 1.48$)$ and negative aspects of social support (OR, 2.12; $95 \% \mathrm{Cl}, 1.4$ to 3.3) were independent risk factors for CFS in the overall sample. Together these risk factors explained ethnic differences in the prevalence of CFS, but no single risk factor could explain a higher prevalence in all ethnic groups.

Conclusions: The prevalence of CFS, but not CF, varies by ethnic group. Anxiety, depression, physical inactivity, social strain and negative aspects of social support together accounted for prevalence differences of CFS in the overall sample.

\section{Background}

Chronic fatigue syndrome (CFS), sometimes also called myalgic encephalomyelitis, is a debilitating condition characterised by unexplained fatigue that lasts for at least 6 months alongside other symptoms that are required for a diagnosis of CFS: headaches, unrefreshing sleep, muscle pain and memory and concentration problems [1]. The prevalence is between 400 and 2,500 adults per 100,000 population [1,2]. Chronic fatigue (CF) alone, without meeting the full criteria for CFS, is

\footnotetext{
* Correspondence: k.s.bhui@qmul.ac.uk

+ Contributed equally

${ }^{1}$ Centre for Psychiatry, Wolson Institute of Preventive Medicine, Barts and the London School of Medicine and Dentistry, Queen Mary University of

London, London, UK

Full list of author information is available at the end of the article
}

more prevalent but less disabling than CFS [3]. Although the exact pathogenesis of CFS is unknown, research implicates infection, endocrine dysfunction, autonomic nervous system imbalance, depressed mood and altered immunity $[1,2]$. Psychosocial factors and physical inactivity have been proposed to be of aetiological significance $[1,2]$, but there is little research on the relative importance of physical inactivity and psychosocial factors in population samples. Cultural factors are known to influence psychosocial risks for many health conditions; therefore, studies in ethnically diverse populations may yield more information about the relative importance of sociocultural, psychological and behavioural risk factors.

Early reports of CFS from clinic populations seemed to suggest that CFS was more common in women,

\section{Biomed Central}


White majority population and the middle classes $[4,5]$. In contrast, some recent population-based research in the United States and the United Kingdom shows that the prevalence of CFS, like many illnesses [6] is actually higher among people of lower socioeconomic status and minority cultural or ethnic groups [3,7-11]. Psychosocial influences include social support, which is a protective factor against CFS [12-14], whereas social strain, including gender disadvantage and financial strain, are known risk factors for poor health in general and for CFS in particular $[7,15]$. Cultural factors include work-related discrimination, assaults and insults; these are more common amongst some ethnic minorities and are important risk factors for a number of health conditions [16-18]. These stressors have not been investigated in CFS.

Although physical illness may potentially explain greater reports of fatigue [19], physical illnesses that cause fatigue are among the exclusion criteria for a diagnosis of CFS [1,2]. For example, the latest international criteria (Centers for Disease Control (CDC), 2006) [20] allow a CFS diagnosis in the presence of long-standing physical illnesses only if these are stable, treated and do not account for fatigue (for example, hypothyroidism, diabetes mellitus and cancer). In contrast, depression and anxiety can cause fatigue and are common in patients with CFS, but are allowable in meeting the CDC criteria for CFS [2,21]. Therefore, ethnic variations in the prevalence of anxiety and depression may explain variations of CFS prevalence.

Some studies suggest that physical activity is an effective intervention for CFS [6]. However, the role of physical inactivity and overactivity in causing CFS is uncertain [2,22-24]. Physical inactivity may play a role in maintaining CFS [25] and is known to be more common among some cultural and ethnic groups. For example, Indian, Pakistani, Bangladeshi and Chinese men and women were the least likely, in a health survey conducted in England, to be as active as recommended in health guidelines [26,27]. Therefore, varying levels of physical activity may explain variations in CFS.

\section{Objectives}

This paper presents the findings of a Medical Research Council (UK)-funded study to estimate the population prevalence of CF and CFS in an ethnically diverse sample. In this study, we tested whether there is a consistently higher prevalence of CF and CFS in specific cultural and ethnic groups and whether variations in prevalence can be explained by social adversity (social strain and perceived discrimination), social support, physical inactivity, anxiety and depression.

Our hypothesis was as follows: (1) CF and CFS show differing patterns of prevalence across ethnic groups, and this difference is independent of variations by age, sex and socioeconomic status; and (2) prevalence variations may be explained by variations in psychosocial risk factors and physical inactivity, such that (a) social adversity such as social strain, low social support and perceived discrimination account for a higher prevalence of CFS; (b) physical inactivity accounts for a higher prevalence of CFS; and (c) anxiety and depression account for a higher prevalence of CFS.

\section{Methods}

Ethical approval for data collection was obtained from the North Thames Multi-Centre Research Ethics Committee and ratified by all Local Research Ethics Committees in England.

\section{The study population}

The Health Survey for England (HSE) comprises a series of annual surveys beginning in 1991. It was designed to provide regular information on the nation's health. The detailed methods used in the Ethnic Minority Psychiatric Illness Rates in the Community (EMPIRIC) study to sample from HSE have been published [27-29]. Therefore, in this paper, we briefly set out the sample methods. The EMPIRIC national population survey took place in 2000 and sampled White British participants from the 1998 Health Survey for England (HSE98) [26]. The 1999 Health Survey for England (HSE99) (the ninth in the series) was the first to increase the representation of ethnic minority groups, boosting the sample of adults from Black Caribbean, Indian, Pakistani, Bangladeshi and Irish communities. So, for the EMPIRIC survey, people from these ethnic groups were sampled starting from HSE99 [27] (see Figure 1). The EMPIRIC survey of 4,281 people ages 16 to 74 years included White British $(n=837)$, White Irish $(n=733)$, Black Caribbean $(n=$ $694)$, Bangladeshi $(n=650)$, Indian $(n=643)$ and Pakistani $(n=724)$ people $[27,28]$. Response rates were highest among the White (71\%) and Irish (72\%) groups and lowest among the Indian group (62\%). Weighting in EMPIRIC analyses ensured that the sample was representative of the population samples in the HSE annual surveys by removing different probabilities of selection. The EMPIRIC study included structured and validated questions about demographic variables and measures of social adversity and measures of anxiety and depression [29].

\section{Measuring CF and CFS}

A question asking about fatigue in the Revised Clinical Interview Schedule (CIS-R) has previously been used to operationally define CF [7] and to validate more extensive measures of CF and CFS [3,30] (see Appendix). Therefore, to define CF and CFS, we used the fatigue question and other stem questions from the CIS-R 


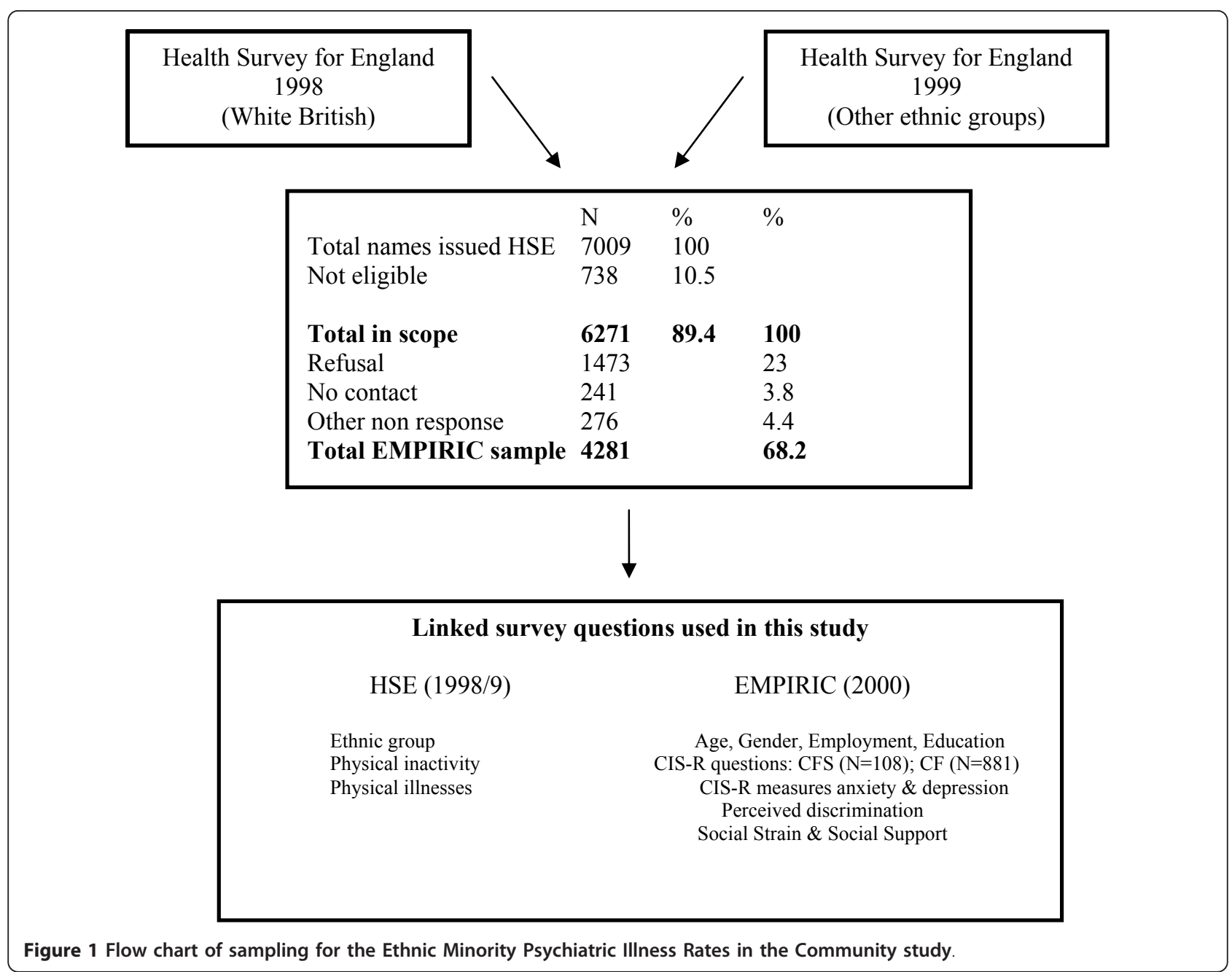

(these questions were distinct from measures of anxiety and depression symptoms). The questions asked about the following symptoms: (1) getting tired and lacking energy and whether there were any reasons for this (such as physical illness), (2) having any problems with concentrating or noticing any problems with forgetting things, (3) having problems with falling asleep or with getting back to sleep, (4) any sort of ache or pain or being troubled by any sort of discomfort such as headache or indigestion.

Participants also rated the duration of symptoms. Using these items, we defined CF as the presence of unexplained fatigue for a period of 6 months. We defined a CFS-like syndrome as closely as possible to the international criteria for CFS [21]. Although the literature does at times make a distinction between CFSlike syndrome and CFS, this is not consistently followed, for example, the published studies on which the methods in this paper were adopted $[3,7,31]$. Therefore, in this paper, we make explicit the study methods and that the operational definition of CFS is compatible with what has been called by some a CFS-like syndrome. We counted as CFS those individuals with all four of the above symptoms, each lasting for at least 6 months. Our definition of at least four symptoms meets the threshold criteria, as CFS is usually diagnosed on the basis of four of eight symptoms, including fatigue [21]. Sensitivity analyses showed that when a fatigue syndrome was defined using fatigue and only two additional symptoms rather than three, the findings from the analyses were identical to the findings for CF. This supported the notion that our definition of CFS did identify a group that was distinct from the CF group.

The EMPIRIC study (2000) [28,29] was undertaken by following up and oversampling people from HSE98 and HSE99 [26,27]. We obtained the individual identifier codes that linked the two data sets, which permitted us to search for physical illnesses reported in HSE98 and HSE99. We were able to identify diseases that might exclude a diagnosis of CFS (31 of 108 (28.7\%) participants met the criteria for CFS): cancer, diabetes, epilepsy, arthritis or fibrositis and infectious or parasitic 
disease. However, we did not know the duration of these physical diseases, whether they were in remission or whether they were causing the fatigue at the time of the HSE survey. Although one analytic approach might be to exclude all those individuals with these physical illnesses, given the lack of information about duration, degree of fatigue and whether it was being treated, this approach might introduce a significant selection bias. We therefore included those participants with the specified conditions in our sample and adjusted for all these illnesses in all of our logistic regression analyses where CFS was an outcome. This adjustment was part of the operational definition; therefore, we do not show the unadjusted analyses. This approach provided estimates of risk independent of physical illnesses that might cause fatigue. This method was supported by sensitivity analyses, which showed that the odds ratios following our analyses did not differ whether we included or excluded people with these physical illnesses. Therefore, using these operational definitions of CF and CFS, linked closely to carefully defined analytic plans, we tested the hypotheses by analysis of data collected in the EMPIRIC study [29].

\section{Measuring common mental disorder}

The EMPIRIC study included the CIS-R, which asks about 14 symptoms in the week preceding a structured interview [32]. Anxiety and depression subscales of the CIS- $\mathrm{R}$ were used in the analyses (both are scored on a scale from 0 to 4 ). These were distinct from the questions about fatigue. The CIS-R shows good face content and construct validity in culturally diverse populations $[28,29,32]$.

\section{Social adversity}

Social class was classified by the head of household's occupation recoded into a 'manual' or 'nonmanual' group. Other measures of socioeconomic position were educational qualifications (recoded into no qualifications, degree or secondary school qualifications, or foreign qualifications) and employment status (employed or unemployed, retired or other economically inactive status). Social support was measured by the Close Persons Questionnaire [31]. Scores were classified using usual validated thresholds into 'low', 'medium' or 'high' levels of confiding or emotional support (seven items), practical support (four items) and negative aspects of close relationships (four items) [31].

Chronic social strain was measured by questions from the Whitehall II study $[15,33]$. The five-point Likert scale responses for each domain were dichotomized: (1) problems with relatives and problems with finances (always, often, sometimes and seldom or never) and (2) problems with essentials, problems with housing and problems with neighbourhood (few or no problems and many or great problems) [33]. These were summed to give a total score (on a scale from 0 to 4 ), where a higher score indicated more frequent (for relatives and finances) or greater social strain. This total score (from 0 to 4$)$ was recoded into tertiles.

Perceived discrimination questions asked about insults in the preceding 12 months; unfair treatment at work regarding promotions; and refusals of employment; and assaults in relation to race, religion or ethnic group. Responses of 'Yes' or 'No' (score of 1 or 0 , respectively) were summed to produce a total discrimination score from 0 to 4 . These questions have been used in previous studies of perceived discrimination and health [34].

\section{Physical inactivity}

Physical activity levels were measured in the HSE98 and HSE99, so they preceded the measures of CF and CFS in the EMPIRIC study (measured in 2000). The intensity of physical activity was assessed by an aggregate measure of the physical demands of people's jobs and four other types of activity: housework, gardening and 'doit-yourself' jobs around the house (including painting, decorating, repairs), walking, sports participation and exercise. The 'intensity level' of activity was already derived in the original HSE data from the estimated energy costs of each activity: vigorous, moderate, light and inactive [26,27]. These were recoded into two groups: vigorous or moderate activity versus no activity or light activity. The number of days in the preceding 4 weeks during which subjects had participated in at least a moderate level of activity for at least 30 minutes daily was the recommended level of healthy activity at the time of the original HSE surveys [35,36]. The total number of active days that each informant reported was divided by four to produce an (average) weekly figure of $<1$ day, 1 to 4 days or 5 or more days weekly, so that the policy and clinical implications for recommended activity might more easily be discerned as activity in an average week. For each activity variable, the highest activity levels (intensity and frequency) were used as the reference group.

\section{Questionnaire and measures}

The EMPIRIC study piloted and then used a structured questionnaire that was available in five languages (Hindi, Gujarati, Punjabi, Urdu and Bengali) [27]. A letter introduced the study before the survey. Gender and language matching were used whenever requested.

\section{Statistical analysis}

All analyses used the survey commands in Stata version 10 software (StataCorp, College Station, TX, USA) and were weighted for probability sampling and nonresponse 
(in HSE99 and EMPIRIC) using established methods with these data to represent population estimates $[27,29]$. Unweighted descriptive data are presented, but all regression models were weighted. Differences between weighted means were assessed using weighted regression, with an overall $P$ value reported. Logistic regression models were built using likelihood ratio (LR) tests to justify inclusion and then retention of variables in the models. Gender did not appear to contribute significantly to the models, but, given its importance, it was retained in all regression models.

The unadjusted associations of demographic factors, including ethnic groups, with CF and CFS are presented in Table 1. Further analyses then investigated univariate associations of social strain, perceived discrimination, social support, physical inactivity and anxiety and depression variables with CFS (Table 2). Table 3 sets out the relationships between these variables and ethnic groups.

Table 4 sets out the nonparametric correlations between demographic and risk factors entered into the final regression model. Table 5 reports manual stepped logistic regression modelling. Explanatory variables were recoded to reduce the number of levels per variable. LR tests were used to justify addition and retention of each of the explanatory variables when added to the basic model. Using this manual stepped approach, we were able to investigate which specific risk factors, when added to the model, led to a reduction in risk in specific ethnic groups or all ethnic groups. The basic model included CFS as an outcome, as well as age (in years), socioeconomic position (measured by education, employment type and whether employed) and ethnicity. We entered social strain, perceived discrimination and social support first; only negative aspects of social support contributed to the model and were retained. Then, in a separate model, we entered physical activity intensity and frequency. The frequency of physical activity did not contribute significantly to the model and was excluded. Starting with the basic model again, we then added anxiety and depression scores (see Table 5). A full model showing independent effects of all of these variables is shown in Table 5.

\section{Results}

\section{Prevalence of CF and CFS}

The weighted prevalence of CFS for the whole sample was $2.3 \%$ (108 of 4,273). The weighted prevalence of CF across the whole sample was $19.7 \%$ (881 of 4,276). CFS prevalence varied by ethnic group, age and educational level and was most prevalent among Pakistani people (Table 1). In contrast, the prevalence of CF varied only by age, sex and marital and employment status, but not by ethnic group (Table 1). The demographic factors associated with CF and CFS are similar (Table 1), but apart from the ethnic group differences, women and retired people have a higher risk of CF but not of CFS. Manual labour workers have a higher risk of CFS but not of CF. People over the age of 35 have a higher risk of CF and CFS in the univariate analyses (reported in Table 1). In the final model (Table 5), a 1-year increase in age is associated with a $2 \%$ ( $95 \%$ confidence interval ( $95 \% \mathrm{CI}), 1 \%$ to $4 \%$ ) higher risk of CFS. As CF did not vary by ethnic group, we did not undertake any further analyses of CF.

When considering univariate associations, chronic social strain, perceived discrimination, the negative aspects of social support, physical inactivity and anxiety and depression were each associated with a higher risk of CFS (Table 2).

Table 3 sets out ethnic variations in measures of social adversity, physical inactivity and anxiety and depression. The Bangladeshi group was more likely to score in the high range on social support (positive and negative) and on social strain. Perceived discrimination scores were highest among the Black Caribbean, Pakistani and Indian groups. Bangladeshi and Pakistani groups were least active as measured on the frequency and intensity of physical activity. Bangladeshi and Pakistani groups had the highest mean depression scores.

\section{Explaining ethnic variations in the prevalence of CFS}

Before reporting regression models, Table 4 sets out the nonparametric correlations between demographic and risk factors entered into the final regression model. This shows highly significant correlations, which are addressed by including these variables in the regression models to show their independent effects.

In regression models, adding chronic strain, perceived discrimination and negative aspects of social support to the basic model led to some reduction in the risk among specific ethnic groups, thus partially explaining the higher prevalence of CFS in some ethnic groups (see Table 5). However, there was little reduction in risk for the Pakistani group (from an odds ratio (OR) of 4.1 (95\% CI, 1.6 to 10.4 ) to an OR of 3.5 (95\% CI, 1.4 to 9.1)). Adding physical inactivity reduced the risk of CFS to a nonsignificant level in all but the Pakistani group. Anxiety and depression alone did not account for ethnic variations in CFS prevalence.

In the full model, age, social strain, negative aspects of social support, physical inactivity and anxiety and depression were independent risk factors for CFS and together explained ethnic variations in CFS prevalence. The point estimates for the Pakistani group especially, and for the other ethnic groups, remained elevated $(>1)$ but were not statistically significant. The full model explained $24 \%$ of the variance. 
Table 1 Demographic characteristics as correlates of CFS and CF (univariate) ${ }^{a}$

\begin{tabular}{|c|c|c|c|c|}
\hline \multirow[b]{2}{*}{ Demographics } & \multicolumn{2}{|c|}{$\mathrm{CF}$} & \multicolumn{2}{|c|}{ CFS } \\
\hline & $\begin{array}{c}\text { Percentage }(n / N), \\
\text { unweighted }\end{array}$ & $\begin{array}{l}\text { OR }(95 \% \mathrm{Cl}) \\
\text { weighted }\end{array}$ & $\begin{array}{c}\text { Percentage }(n / N), \\
\text { unweighted }\end{array}$ & $\begin{array}{l}\text { OR }(95 \% \mathrm{Cl}) \\
\text { weighted }\end{array}$ \\
\hline \multicolumn{5}{|l|}{ Ethnic group } \\
\hline White & $22.6(189 / 836)$ & 1 & $0.8(7 / 835)$ & 1 \\
\hline Irish & $21.7(159 / 732)$ & $1(0.7$ to 1.3$)$ & $2.0(15 / 732)$ & 2.6 (0.98 to 6.9 ) \\
\hline Black Caribbean & $19.8(137 / 691)$ & 0.8 (0.6 to 1.01$)$ & $2.5(17 / 690)$ & $2.6(1.04 \text { to } 6.7)^{b}$ \\
\hline Bangladeshi & $19.4(126 / 650)$ & 0.8 (0.6 to 1.03$)$ & $3.4(22 / 650)$ & $3.2(1.3 \text { to } 7.8)^{\mathrm{b}}$ \\
\hline Indian & $19.3(124 / 643)$ & 0.8 (0.6 to 1.1$)$ & $3.1(20 / 643)$ & $3.3(1.3 \text { to } 8.3)^{c}$ \\
\hline Pakistani & $20.2(146 / 724)$ & 0.8 (0.6 to 1.04$)$ & $3.7(27 / 723)$ & $4.3(1.7 \text { to } 10.5)^{d}$ \\
\hline \multicolumn{5}{|l|}{ Sex } \\
\hline Male & $19(368 / 1,939)$ & 1 & $2.6(50 / 1,937)$ & 1 \\
\hline Female & $22(513 / 2,337)$ & $1.2(1.01 \text { to } 1.4)^{\mathrm{b}}$ & $2.5(58 / 2,336)$ & 0.9 (0.6 to 1.4$)$ \\
\hline \multicolumn{5}{|l|}{ Age group, yr } \\
\hline 16 to 34 & $12(198 / 1,646)$ & 1 & $0.7(12 / 1,645)$ & 1 \\
\hline 35 to 54 & $24.2(416 / 1,720)$ & $2.5(2 \text { to } 3)^{d}$ & $3.5(60 / 1,718)$ & $5.4(2.5 \text { to } 11.4)^{d}$ \\
\hline 55 to 74 & $29.3(267 / 910)$ & $3.3(2.7 \text { to } 4.2)^{d}$ & $4.0(36 / 910)$ & $5.5(2.5 \text { to } 12.1)^{d}$ \\
\hline \multicolumn{5}{|l|}{ Marital status } \\
\hline Married & $22.4(617 / 2,752)$ & 1 & $2.9(80 / 2,751)$ & 1 \\
\hline Divorced/separated & $31.1(97 / 312)$ & $1.5(1.5 \text { to } 1.9)^{c}$ & $3.8(12 / 312)$ & $1.2(0.6$ to 2.5$)$ \\
\hline Widowed & $28.5(45 / 158)$ & 1.2 (0.8 to 1.8$)$ & $3.8(6 / 158)$ & 1.4 (0.6 to 3.7 ) \\
\hline Single & $11.6(122 / 1,054)$ & $0.5(0.4 \text { to } 0.6)^{d}$ & $1(10 / 1,052)$ & $0.4(0.2 \text { to } 0.9)^{\mathrm{b}}$ \\
\hline \multicolumn{5}{|l|}{ Employment status } \\
\hline Employed & $17.5(397 / 2,272)$ & 1 & $1.5(35 / 2,271)$ & 1 \\
\hline Unemployed & $17.9(30 / 168)$ & 0.9 (0.6 to 1.5$)$ & $2.4(4 / 168)$ & 0.9 (0.3 to 3.5$)$ \\
\hline Retired & $30.6(144 / 470)$ & $1.6(1.2 \text { to } 2.1)^{d}$ & $3.4(16 / 470)$ & 1.7 (0.8 to 3.4 ) \\
\hline Other economically inactive & $23.4(290 / 1,238)$ & $1.2(1.1 \text { to } 1.5)^{\mathrm{b}}$ & $4.0(49 / 1,236)$ & $2.1(1.3 \text { to } 3.4)^{c}$ \\
\hline \multicolumn{5}{|l|}{ Educational level } \\
\hline Degree or above & $19.2(188 / 977)$ & 1 & $1.4(14 / 976)$ & 1 \\
\hline A level/GCSE & $17.9(275 / 1,536)$ & $0.9(0.7$ to 1.1$)$ & $2.0(30 / 1,534)$ & 1.5 (0.7 to 3.2$)$ \\
\hline Foreign qualification & $23.3(38 / 163)$ & $1.2(0.8$ to 1.9$)$ & $2.5(4 / 163)$ & 2.3 (0.6 to 8.3$)$ \\
\hline No qualification & $25.5(375 / 1,468)$ & $1.4(1.1 \text { to } 1.7)^{c}$ & $4.0(59 / 1,468)$ & $2.8(1.4 \text { to } 5.7)^{c}$ \\
\hline \multicolumn{5}{|l|}{$\begin{array}{l}\text { Type of employment (head of } \\
\text { household) }\end{array}$} \\
\hline Nonmanual labour & $19.7(334 / 1,693)$ & 1 & $1.7(29 / 1,692)$ & 1 \\
\hline Manual labour & $20.8(484 / 2,326)$ & $1(0.8$ to 1.2$)$ & $2.9(68 / 2324)$ & $1.6(0.99 \text { to } 2.6)^{b}$ \\
\hline \multicolumn{5}{|l|}{ Place of birth } \\
\hline United Kingdom & $16.1(238 / 1,476)$ & 1 & $1.1(16 / 1,475)$ & 1 \\
\hline Other & $23(459 / 1,993)$ & $1.3(1.1 \text { to } 1.6)^{c}$ & $4.2(84 / 1,992)$ & $3.5(1.8 \text { to } 6.8)^{d}$ \\
\hline \multicolumn{5}{|l|}{ Age of migration, $y r$} \\
\hline$<11$ & $16.7(391 / 2,335)$ & 1 & $1.2(28 / 2,333)$ & 1 \\
\hline$\geq 11$ & $21.6(223 / 1,031)$ & $1.3(1.1 \text { to } 1.6)^{c}$ & $4.3(44 / 1,030)$ & $4.2(2.4 \text { to } 7.4)^{d}$ \\
\hline
\end{tabular}

${ }^{a}$ CFS, chronic fatigue syndrome; $\mathrm{CF}$, chronic fatigue; OR, odds ratio; $95 \% \mathrm{Cl}, 95 \%$ confidence interval; ${ }^{\mathrm{b}} P \leq 0.05 ;{ }^{\mathrm{c}} P \leq 0.01 ;{ }^{\mathrm{d}} P \leq 0.001$.

${ }^{\mathrm{e}} \mathrm{A}$ Level $=$ Advanced Level/GCSE $=$ General Certificate of Secondary Education.

\section{Discussion}

This is the first population study of both CF and CFS to include a large, ethnically diverse sample (six ethnic groups). The overall weighted prevalence of $2.3 \%$ for CFS is similar to the $2.6 \%$ found in the previous largest study of CFS in U.K. primary care [3]. Overall, the findings from this study suggest that most ethnic minority groups have a higher risk for CFS, but not for CF, when compared to White people. Although early studies indicated that CFS was uncommon among ethnic minorities $[4,5]$, our study is consistent with research that shows that this may be related to the selection bias of clinic attenders rather than a lower prevalence of CFS [37].

Middle age is reported to be a high-risk period for developing CFS, and a higher risk is expected in those over 38 years of age [38]. Although many explanations 
Table 2 Social, health and physical inactivity correlates of CFS (univariate) ${ }^{\mathrm{a}}$

\begin{tabular}{|c|c|c|}
\hline CFS correlate & Percentage $(n / N)$, unweighted & OR $(95 \% \mathrm{Cl})$, weighted \\
\hline \multicolumn{3}{|l|}{ Social support } \\
\hline \multicolumn{3}{|c|}{ Confiding/emotional support } \\
\hline Low & $3.1(35 / 1,132)$ & 1 \\
\hline Average & $2.3(38 / 1,675)$ & 0.7 (0.4 to 1.3$)$ \\
\hline High & $2.4(33 / 1,398)$ & $0.8(0.5$ to 1.5$)$ \\
\hline \multicolumn{3}{|l|}{ Practical support } \\
\hline Low & $1.9(16 / 861)$ & 1 \\
\hline Average & $2.1(28 / 1,317)$ & 0.99 (0.5 to 2$)$ \\
\hline High & $3.1(62 / 2,032)$ & 1.4 (0.7 to 2.7$)$ \\
\hline \multicolumn{3}{|c|}{ Negative aspects of support } \\
\hline Low & $0.6(4 / 631)$ & 1 \\
\hline Average & $2(30 / 1,472)$ & 2.3 (0.7 to 7.6$)$ \\
\hline High & $3.4(72 / 2,103)$ & $4(1.2 \text { to } 12.4)^{\mathrm{b}}$ \\
\hline \multicolumn{3}{|l|}{ Chronic strains } \\
\hline \multicolumn{3}{|l|}{ Tertiles of total score } \\
\hline Low & $0.9(9 / 1,023)$ & 1 \\
\hline Average & $2.2(46 / 2,124)$ & $2.3(1.04 \text { to } 5)^{b}$ \\
\hline High & $4.8(53 / 1,100)$ & $4.9(2.2 \text { to } 10.6)^{c}$ \\
\hline \multicolumn{3}{|l|}{ Perceived discrimination } \\
\hline Total score (means) & - & $1.5(1.1 \text { to } 2)^{d}$ \\
\hline \multicolumn{3}{|c|}{ Mental health (CIS-R subscales) } \\
\hline Depression score & - & $2.2(1.9 \text { to } 2.6)^{c}$ \\
\hline Anxiety score & - & $2.2(1.9 \text { to } 2.6)^{c}$ \\
\hline \multicolumn{3}{|l|}{ Physical inactivity } \\
\hline \multicolumn{3}{|c|}{ Days of moderate activity of $\geq 30$ minutes/day in past 4 weeks ${ }^{b}$} \\
\hline 5 or more (high) & $1.4(16 / 1,126)$ & 1 \\
\hline 1 to 4 (medium) & $1.3(16 / 1,256)$ & $1.02(0.4$ to 2.3$)$ \\
\hline 1 or $<1$ (low) & $4(75 / 1,883)$ & 3.3 (1.7 to 6.2$)$ \\
\hline \multicolumn{3}{|l|}{ Activity intensity } \\
\hline Moderate/vigorous & $1.7(55 / 3,217)$ & 1 \\
\hline Inactive/light & $5.7(53 / 926)$ & $4.6(2.9$ to 7.2$)$ \\
\hline
\end{tabular}

${ }^{a}$ CFS, chronic fatigue syndrome; OR, odds ratio; $95 \% \mathrm{Cl}, 95 \%$ confidence interval; CIS-R, Revised Clinical Interview Schedule; ${ }^{\mathrm{b}} P \leq 0.05 ;{ }^{\mathrm{c}} P \leq 0.001 ;{ }^{\mathrm{d}} P \leq 0.01$.

exist for fatigue in older people, even after recovery from physical illness, the National Institute on Aging (in the United States) did not find a consistently higher risk among older adults or a rise in risk with age (http:// www.nia.nih.gov/researchinformation/conferencesandmeetings/unexplainedfatigue.htm). Indeed, in contrast, a recent study validating a fatigue measure showed a lower fatigue score with increasing age [39]. We adjusted for physical illnesses that might explain fatigue symptoms, and therefore comorbid physical illnesses are unlikely to explain the findings of rising risk of CFS with age.

Overall, physically inactive people were twice as likely to have CFS compared with active individuals. However, physical inactivity may emerge following the onset of CFS as a way of avoiding fatigue; once physical inactivity emerges, deconditioning can occur and can further compound fatigue [25]. Prospective studies have suggested that fatigue is more commonly found in those who were physically active earlier in their lives [23]. In contrast to the longitudinal analysis of the 1946 birth cohort [24], we did not find a higher risk of CFS among the very active or the very inactive (data not shown). We could not identify a subgroup within our active group who might be irregularly involved in activity, as our estimates of activity were averages. Future research might also investigate whether increasing population levels of physical activity reduce the future risk of CFS or indeed increase it as suggested in one cohort study, as well as whether irregular patterns of activity rather than inactivity are significant predictors of fatigue [36].

Anxiety and depression did not alone explain the ethnic variations in CFS prevalence. The findings suggest that the risk of CFS overall is increased by $49 \%$ for each point on the depression score and by $80 \%$ for each point on the anxiety score. Although the survey was 
Table 3 Demographics, social, illness and physical activity characteristics of survey population by ethnicity ${ }^{a}$

\begin{tabular}{|c|c|c|c|c|c|c|c|c|}
\hline \multirow[b]{2}{*}{ Demographic variable } & \multicolumn{8}{|c|}{ Sample size, $n(\%)$} \\
\hline & Total, $N(\%)$ & White & Irish & Black Caribbean & Bangladeshi & Indian & Pakistani & $P$ value \\
\hline & & $835(19.5)$ & $733(17.1)$ & $691(16.1)$ & $650(15.2)$ & $648(15.1)$ & $724(16.9)$ & \\
\hline \multicolumn{9}{|l|}{ Sex } \\
\hline Male & $1,950(45.5)$ & $365(43.7)$ & $323(44.1)$ & $280(40.5)$ & $321(49.4)$ & $316(48.8)$ & $345(47.7)$ & $\leq 0.04$ \\
\hline Female & $2,332(54.5)$ & $471(56.1)$ & $410(55.9)$ & $412(59.5)$ & $329(50.6)$ & $331(51.2)$ & $379(52.3)$ & \\
\hline \multicolumn{9}{|l|}{ Age, yr } \\
\hline 16 to 34 & $1,774(41.4)$ & $260(31.1)$ & $209(28.5)$ & $269(38.9)$ & $376(57.8)$ & $248(38.3)$ & $412(56.9)$ & $\leq 0.001$ \\
\hline 35 to 54 & $1,647(38.5)$ & $355(42.5)$ & $345(47.1)$ & $251(36.3)$ & $187(28.7)$ & $280(43.2)$ & $229(21.6)$ & \\
\hline 55 to 74 & $862(20.1)$ & $221(26.4)$ & $179(24.4)$ & $171(24.7)$ & $88(13.5)$ & $120(18.5)$ & $83(11.5)$ & \\
\hline \multicolumn{9}{|l|}{ Marital status } \\
\hline Married & $2,674(62.5)$ & $518(62.1)$ & $461(62.8)$ & $279(40.4)$ & $446(68.7)$ & 464 (71.7) & $506(69.9)$ & $\leq 0.001$ \\
\hline Divorced/separated & $313(7.3)$ & $75(9)$ & 78 (10.6) & $84(12.2)$ & $18(2.8)$ & $32(4.9)$ & $26(3.6)$ & \\
\hline Widowed & $142(3.3)$ & $36(4.3)$ & $25(3.4)$ & $18(2.6)$ & $28(4.3)$ & $19(2.9)$ & $16(2.2)$ & \\
\hline Single & $1,150(26.9)$ & $205(24.6)$ & $170(23.2)$ & $310(44.9)$ & $157(24.2)$ & $132(20.4)$ & $176(24.3)$ & \\
\hline \multicolumn{9}{|l|}{ Employment status } \\
\hline Employed & $2,273(55)$ & $536(66.4)$ & $490(69)$ & $376(57.4)$ & $181(29.1)$ & $394(61.9)$ & $296(42.4)$ & $\leq 0.001$ \\
\hline Unemployed & $168(4.1)$ & $10(1.2)$ & $12(1.7)$ & $39(6)$ & $40(6.4)$ & $33(5.2)$ & $34(4.9)$ & \\
\hline Retired & $446(10.8)$ & $130(16.1)$ & $96(13.5)$ & $97(14.8)$ & $33(5.3)$ & $49(7.7)$ & $41(5.9)$ & \\
\hline Other economically inactive & $1,242(30.1)$ & $131(16.2)$ & $112(15.8)$ & $143(21.8)$ & $369(59.2)$ & $160(25.2)$ & $327(46.8)$ & \\
\hline \multicolumn{9}{|l|}{ Educational level } \\
\hline Degree or above & $951(23.2)$ & $213(26.5)$ & $195(27.6)$ & $172(26)$ & $62(10.1)$ & $187(29.9)$ & $122(17.8)$ & $\leq 0.001$ \\
\hline A level/GCSE & $1,549(37.8)$ & $356(44.3)$ & $294(41.6)$ & $272(41.1)$ & $172(27.9)$ & $221(35.3)$ & $234(34.1)$ & \\
\hline Foreign qualification & $172(4.2)$ & $32(4)$ & $35(5)$ & $30(4.5)$ & $17(2.8)$ & $29(4.6)$ & $29(4.2)$ & \\
\hline No qualification & $1,428(34.8)$ & $202(25.2)$ & $183(25.9)$ & $188(28.4)$ & $365(59.3)$ & $189(30.2)$ & $301(43.9)$ & \\
\hline \multicolumn{9}{|l|}{ Social class (employment type) } \\
\hline Nonmanual labour & $1,681(41.9)$ & $463(56.3)$ & $351(48.5)$ & $279(42.7)$ & $92(16.4)$ & $279(44.6)$ & $217(34.5)$ & $\leq 0.001$ \\
\hline Manual labour & $2,335(58.1)$ & $360(43.7)$ & $372(51.5)$ & $375(57.3)$ & $469(83.6)$ & $347(55.4)$ & $412(65.5)$ & \\
\hline \multicolumn{9}{|l|}{ Social support scores (tertiles) } \\
\hline Confiding/emotional support & & & & & & & & $\leq 0.001$ \\
\hline Low & $1,137(27)$ & $225(27.1)$ & $194(26.8)$ & $226(33.5)$ & $154(24)$ & $168(26.5)$ & $170(24.1)$ & \\
\hline Average & $1,667(39.6)$ & $301(36.3)$ & $244(33.7)$ & $239(35.4)$ & $313(48.8)$ & $262(41.4)$ & $308(43.7)$ & \\
\hline High & 1,404 (33.4) & $303(36.6)$ & $287(39.6)$ & $210(31.1)$ & $174(27.1)$ & $203(32.1)$ & $227(32.2)$ & \\
\hline Practical support & & & & & & & & $\leq 0.001$ \\
\hline Low & $892(21.2)$ & $200(24.1)$ & $149(20.5)$ & $179(26.5)$ & 68 (10.6) & $145(22.9)$ & $151(21.4)$ & \\
\hline Average & $1,308(31)$ & $296(35.7)$ & $259(35.7)$ & $253(37.4)$ & $130(20.3)$ & $185(29.2)$ & $185(26.2)$ & \\
\hline High & $2,013(47.8)$ & $334(40.2)$ & $318(43.8)$ & $244(36.1)$ & $443(69.1)$ & $303(47.9)$ & $371(52.5)$ & \\
\hline Negative aspects of support & & & & & & & & $\leq 0.001$ \\
\hline Low & $646(15.4)$ & $159(19.2)$ & $113(15.6)$ & $135(20)$ & $31(4.9)$ & $100(15.8)$ & $108(15.3)$ & \\
\hline Average & $1,484(35.3)$ & $365(44)$ & $331(45.6)$ & $225(33.3)$ & $126(19.7)$ & $200(31.6)$ & $237(33.6)$ & \\
\hline High & $2,078(49.4)$ & $306(36.9)$ & $282(38.8)$ & $316(46.7)$ & $481(75.4)$ & $332(52.5)$ & $361(51.1)$ & \\
\hline Chronic strain mean scores $^{\mathrm{b}}$ & 1.62 & 1.34 & 1.44 & 1.71 & 2.31 & 1.38 & 1.53 & $\leq 0.0001$ \\
\hline Perceived discrimination mean scores ${ }^{b}$ & 0.30 & 0.13 & 0.15 & 0.65 & 0.19 & 0.39 & 0.35 & $\leq 0.0001$ \\
\hline $\begin{array}{l}\text { Days of moderate activity } \\
\geq 30 \text { minutes/day in past } 4 \text { weeks }\end{array}$ & & & & & & & & $\leq 0.001$ \\
\hline 5 or more (high) & $1,131(26.5)$ & $268(32.1)$ & $231(31.6)$ & $228(33.1)$ & $93(14.3)$ & $170(26.2)$ & $141(19.5)$ & \\
\hline 1 to 4 (medium) & $1,274(29.8)$ & $278(33.3)$ & $247(33.7)$ & $201(29.2)$ & $139(21.4)$ & $192(29.6)$ & $217(30.1)$ & \\
\hline 1 or <1 (low) & $1,870(43.7)$ & $288(34.5)$ & $254(34.7)$ & $260(37.7)$ & $418(64.3)$ & $286(44.1)$ & $364(50.4)$ & \\
\hline Activity intensity & & & & & & & & $\leq 0.001$ \\
\hline Inactive/light & $903(22)$ & $6(0.7)$ & $102(14.4)$ & $116(17.4)$ & $308(49.9)$ & $156(24.9)$ & $215(31.3)$ & \\
\hline Moderate/vigorous & $3,201(78)$ & $795(99.3)$ & $606(85.6)$ & $549(82.6)$ & $309(50.1)$ & $470(75.1)$ & $472(68.7)$ & \\
\hline
\end{tabular}


Table 3 Demographics, social, illness and physical activity characteristics of survey population by ethnicity ${ }^{\mathrm{a}}$ (Continued)

\begin{tabular}{|c|c|c|c|c|c|c|c|c|}
\hline Anxiety mean scores ${ }^{\mathrm{b}}$ & 0.30 & 0.31 & 0.38 & 0.29 & 0.20 & 0.29 & 0.32 & 0.005 \\
\hline Depressive mean scores ${ }^{\mathrm{b}}$ & 0.43 & 0.41 & 0.41 & 0.42 & 0.36 & 0.46 & 0.51 & 0.003 \\
\hline
\end{tabular}

${ }^{\mathrm{a} G C S E}$ : General Certificate of Secondary Education. ${ }^{\mathrm{b}}$ weighted mean.

cross-sectional in nature and reverse causality may be an important explanation, previous research has shown that anxiety and depression can increase the risk of later CFS [23] and may share with CFS predisposing risk factors such as infectious illness [40,41].

CFS may reflect the influence of social status, power and exposure to adversity. Those with negative aspects of social support were twice as likely to have CFS, and those with social strain were $40 \%$ more likely to have CFS. Anthropological and biological critiques suggest that physiological symptoms, such as fatigue, can be an expression of social pressures related to minority status, including discrimination and social strain [42]. This has not been tested previously in epidemiological studies. This study offers some confirmation that chronic social strain and negative aspects of social support explain some of the higher risk of CFS among ethnic groups, but perceived discrimination was not statistically significantly associated with CFS in the final models. Ethnic group differences in the findings following adjustments are probably explained by each ethnic group's differing profile of risk factors; for example, exposure to discrimination and social strain, levels of physical inactivity and levels of anxiety and depression differ by ethnic group (Table 3). Our final models show independent effects of anxiety, depression, physical inactivity, social strain, negative aspects of social support and age in the whole population. Coping and help-seeking may also vary with culture and ethnic group [28]. We did not measure coping mechanisms or help-seeking for CF and CFS. As these are important in service-based studies that investigate access and recovery, they do not account for our population-based findings. Studies of recovery from CFS by ethnic group are needed to investigate whether different health beliefs and coping styles influence clinical outcomes. A qualitative component of the EMPIRIC study is investigating these aspects using secondary data analysis of qualitative data.

\section{Limitations}

The study is the largest of ethnic groups in the United Kingdom, but even larger samples are needed to test for interactions between specific risk factors for specific ethnic groups. The classification of ethnic groups is undergoing constant revision. We were reliant on the categories used for the census in the United Kingdom, which were used in the HSE and EMPIRIC surveys. Ethnic minority status remains an important category by which inequalities are assessed. The treatment of anxiety and depression symptoms remains important, even if some consider that these are a consequence rather than a cause of CF and CFS. Studies of physical illness as aetiological factors in CFS are difficult to undertake, given the various exclusion criteria requiring detailed clinical information about the timing of fatigue and other illnesses. We were not able to address this question in this study. As we did not have biomarkers, this study was not able to test for other causes of fatigue, for example, we did not have measures of immune response or endocrine function.

The operational definition of CFS that we used in this study conforms to what has been called a 'CFS-like' illness in some published research; yet, even within the

Table 4 Relationship between independent variables with each other (Spearman's $\rho$ )

\begin{tabular}{|c|c|c|c|c|c|c|c|c|c|c|}
\hline Variable & Sex & Age & Education & Employment & $\begin{array}{l}\text { Social } \\
\text { strain }\end{array}$ & Discrimination & $\begin{array}{c}\text { Negative social } \\
\text { support }\end{array}$ & $\begin{array}{l}\text { Physical } \\
\text { inactivity }\end{array}$ & Depression & Anxiety \\
\hline Sex & 1.000 & & & & & & & & & \\
\hline Age & $-0.0400^{a}$ & & & & & & & & & \\
\hline Education & $-0.0381^{a}$ & $-0.2628^{d}$ & 1.0000 & & & & & & & \\
\hline Employment & $0.2070^{d}$ & $0.1481^{d}$ & $-0.3573^{d}$ & 1.0000 & & & & & & \\
\hline Social strain & $0.0674^{d}$ & $-0.1135^{d}$ & $-0.0777^{d}$ & $0.1089^{d}$ & 1.0000 & & & & & \\
\hline Discrimination & $-0.1176^{d}$ & $-0.0397^{b}$ & $0.1288^{d}$ & $-0.1038^{d}$ & $0.1293^{d}$ & 1.0000 & & & & \\
\hline $\begin{array}{l}\text { Negative social } \\
\text { support }\end{array}$ & $0.0445^{b}$ & $-0.1189^{d}$ & $-0.0443^{b}$ & $0.0753^{d}$ & $0.2077^{d}$ & $0.0467^{b}$ & 1.0000 & & & \\
\hline $\begin{array}{l}\text { Physical } \\
\text { inactivity }\end{array}$ & -0.0135 & $0.1103^{d}$ & $-0.2693^{d}$ & $0.2538^{d}$ & $0.0947^{d}$ & $-0.0487^{b}$ & $0.1186^{d}$ & 1.0000 & & \\
\hline Depression & $0.0529^{c}$ & -0.0060 & -0.0096 & $0.0564^{c}$ & $0.1768^{d}$ & $0.0943^{d}$ & $0.0913^{d}$ & $0.0727^{d}$ & 1.0000 & \\
\hline Anxiety & $0.0537^{d}$ & -0.0038 & $0.0462^{\mathrm{b}}$ & 0.0154 & $0.1884^{d}$ & $0.0730^{d}$ & $0.0879^{d}$ & -0.0187 & $0.3617^{d}$ & 1.0000 \\
\hline
\end{tabular}

${ }^{\mathrm{a}} P<0.05 ;{ }^{\mathrm{b}} P<0.01 ;{ }^{\mathrm{c}} P<0.001 ;{ }^{\mathrm{d}} P<0.0001$. 
Table 5 Stepped and full logistic regression models showing associations with CFS $^{\mathrm{a}}$

\begin{tabular}{|c|c|c|c|c|c|c|c|c|c|c|c|c|c|c|c|}
\hline & \multicolumn{3}{|c|}{$\begin{array}{c}\text { Basic model } \\
\left(N=3,794 ; R^{2}=0.05\right)\end{array}$} & \multicolumn{3}{|c|}{$\begin{array}{c}\text { Basic model and social } \\
\text { variables } \\
\left(N=3,741 ; R^{2}=0.14\right)\end{array}$} & \multicolumn{3}{|c|}{$\begin{array}{c}\text { Basic model and physical } \\
\text { inactivity } \\
\left(N=3,792 ; R^{2}\right.\end{array}$} & \multicolumn{3}{|c|}{$\begin{array}{c}\text { Basic model and psychological } \\
\text { variables } \\
\left(N=3,794 ; R^{2}\right.\end{array}$} & \multicolumn{3}{|c|}{$\begin{array}{l}\text { Full model } \\
\left(N=3,739 ; R^{22}\right.\end{array}$} \\
\hline & $\overline{O R}$ & $95 \% \mathrm{Cl}$ & $P$ value & OR & $95 \% \mathrm{Cl}$ & $P$ value & OR & $95 \% \mathrm{Cl}$ & $P$ value & OR & $95 \% \mathrm{Cl}$ & $P$ value & OR & $95 \% \mathrm{Cl}$ & $P$ value \\
\hline \multicolumn{16}{|l|}{ Ethnicity } \\
\hline Irish & 2.12 & 0.8 to 5.71 & 0.13 & 1.96 & 0.70 to 5.44 & 0.2 & 1.76 & 0.64 to 4.80 & 0.27 & 2.25 & 0.83 to 6.09 & 0.108 & 1.72 & 0.58 to 5.1 & 0.32 \\
\hline Black Caribbean & 2.33 & 0.90 to 5.98 & 0.078 & 1.48 & 0.55 to 4.02 & 0.44 & 1.80 & 0.70 to 4.60 & 0.22 & 2.62 & 1.02 to 6.74 & 0.045 & 1.65 & 0.58 to 4.68 & 0.34 \\
\hline Bangladeshi & 3.24 & 1.17 to 9.01 & 0.02 & 1.54 & 0.55 to 4.34 & 0.41 & 1.89 & 0.62 to 5.68 & 0.26 & 4.5 & 1.61 to 12.4 & 0.004 & 1.87 & 0.61 to 5.75 & 0.27 \\
\hline Indian & 2.51 & 0.97 to 6.53 & 0.057 & 2.01 & 0.73 to 5.50 & 0.17 & 1.77 & 0.65 to 4.84 & 0.26 & 2.33 & 0.86 to 6.3 & 0.093 & 1.51 & 0.5 to 4.6 & 0.45 \\
\hline Pakistani & 4.09 & 1.6 to 10.44 & 0.003 & 3.34 & 1.27 to 8.75 & 0.01 & 2.71 & 1.01 to 7.30 & 0.048 & 3.74 & 1.39 to 10.05 & 0.009 & 2.49 & 0.83 to 7.45 & 0.10 \\
\hline Sex & 0.98 & 0.59 to 1.65 & 0.96 & 1.01 & 0.59 to 1.73 & 0.95 & 1.02 & 0.61 to 1.70 & 0.92 & 0.88 & 0.51 to 1.51 & 0.645 & 0.91 & 0.53 to 1.56 & 0.74 \\
\hline Age & 1.02 & 1.01 to 1.03 & 0.002 & 1.03 & 1.02 to 1.05 & $<0.001$ & 1.01 & 1.01 to 1.03 & 0.015 & 1.03 & 1.01 to 1.04 & 0.001 & 1.02 & 1.01 to 1.04 & 0.001 \\
\hline Education & 0.95 & 0.52 to 1.74 & 0.87 & 0.85 & 0.45 to 1.59 & 0.61 & 0.98 & 0.53 to 1.82 & 0.96 & 0.91 & 0.48 to 1.75 & 0.795 & 0.85 & 0.44 to 1.66 & 0.65 \\
\hline Employment & 1.18 & 0.66 to 2.12 & 0.56 & 1.20 & 0.66 to 2.18 & 0.55 & 1.07 & 0.59 to 1.93 & 0.82 & 0.90 & 0.49 to 1.68 & 0.760 & 0.86 & 0.44 to 1.68 & 0.67 \\
\hline Type of employment & 1.27 & 0.74 to 2.17 & 0.38 & 1.24 & 0.71 to 2.17 & 0.44 & 1.22 & 0.71 to 2.09 & 0.46 & 1.26 & 0.71 to 2.24 & 0.41 & 1.18 & 0.65 to 2.14 & 0.57 \\
\hline Strain (score) & & & & 1.44 & 1.08 to 1.94 & $<0.0001$ & & & & & & & 1.22 & 1.02 to 1.47 & 0.03 \\
\hline Discrimination (score) & & & & 1.45 & 1.08 to 1.95 & 0.01 & & & & & & & 1.28 & 0.92 to 1.78 & 0.15 \\
\hline $\begin{array}{l}\text { Negative aspects } \\
\text { of social support }\end{array}$ & & & & 2.12 & 1.37 to 3.28 & 0.001 & & & & & & & 2.0 & 1.25 to 3.2 & 0.004 \\
\hline $\begin{array}{l}\text { Physical in activity } \\
\text { (moderate/vigorous } \\
\text { vs. inactive/light) }\end{array}$ & & & & & & & 2.33 & 1.37 to 4.00 & 0.001 & & & & 2.17 & 1.13 to 4.16 & 0.02 \\
\hline Depression score & & & & & & & & & & 1.59 & 1.27 to 1.99 & 0.001 & 1.49 & 1.17 to 1.89 & 0.001 \\
\hline Anxiety score & & & & & & & & & & 1.91 & 1.54 to 2.39 & 0.001 & 1.80 & 1.43 to 2.27 & $<0.001$ \\
\hline
\end{tabular}

${ }^{2} \mathrm{CFS}$, chronic fatigue syndrome; $\mathrm{OR}$, odds ratio; $95 \% \mathrm{Cl}, 95 \%$ confidence interval. All variables were identified by likelihood ratio (LR) tests to contribute to the basic model, including age and socioeconomic status (SES) variables (education, none vs. some; employment of head of household, manual vs. nonmanual; employed, no vs. yes). Head of household and employment contributed significantly to the model when considered on their own, whereas education did not. However, when all three SES variables were considered together, they contributed significantly to the model. Sex did not contribute to models using the LR test and changed ORs only slightly. Age of migration and place of birth were tested after the demographic variables were entered, but did not contribute significantly to the model. They were also tested in the final model and made no difference in the results, so they were not retained. All analyses were weighted and adjusted for physical illnesses that might explain fatigue. 
'CFS-like' grouping, there are many variations in classification. Clinical studies and replication studies are necessary to test for risk factors amongst those developing CFS in accordance with full clinical diagnostic criteria. Similarly, we were not able to assess psychosomatic illnesses and their relationships with CFS. Clinical studies using independent and valid measures of psychosomatic illnesses in ethnic groups may be especially helpful, given that some ethnic groups are reported to have more psychosomatic illnesses.

Ethnic group-specific analysis might be helpful to establish risk factors for specific ethnic groups; however, although this study remains the largest population sample of ethnic groups in England, it is inadequately powered to assess the precise effects and interactions between the risk factors in each ethnic group separately.

\section{Conclusion}

This study indicates that CFS is associated with social strain, negative aspects of social support, physical inactivity, anxiety and depression. These associations together explain the higher risks among some ethnic groups.

\section{Appendix: Fatigue questions}

Have you noticed that you've been getting tired in the past month?

1. Yes

2. No

During the past month, have you felt you've been lacking in energy?

1. Yes

2. No

Do you know why you have been feeling tired or lacking in energy?

1. Yes

2. No

What is the main reason?

1. Problems with sleep

2. Medication

3. Physical illness

4. Working too hard (including housework, looking after baby)

5. Stress, worry or other psychological reason

6. Physical exercise

7. Other (specify)

In the past seven days, on how many days have you felt tired or lacking in energy?

1. 4 days or more

2. 1 to 3 days

3. None

\section{Acknowledgements}

This work was supported by the Medical Research Council in the UK (grant G0500978 to KSB in 2006).

\section{Author details}

'Centre for Psychiatry, Wolson Institute of Preventive Medicine, Barts and the London School of Medicine and Dentistry, Queen Mary University of London, London, UK. ${ }^{2}$ Division of Epidemiology, Public Health and Primary Care, Imperial College London, UK. ${ }^{3}$ School of Social Sciences, University of Manchester, Manchester, UK. ${ }^{4}$ Department of Psychological Medicine and Psychiatry, Institute of Psychiatry, King's College London, London, UK.

\section{Authors' contributions}

KSB conceived of the study, was the principal investigator, provided day-today management and drafted the manuscript. SD prepared and managed the data sets and carried out the statistical analyses. DA supervised statistical analyses and gave expert advice on nested models. JN and SW gave advice on all different phases of the study and gave particular help in forming the objectives of the study. PDW gave advice on the design and data analysis stages of the study, the definition of CFS and in shaping the conclusions of the study. All authors commented on and edited all drafts of the manuscript. All authors read and approved the final manuscript.

\section{Competing interests}

The authors declare that they have no competing interests.

Received: 1 November 2010 Accepted: 21 March 2011

Published: 21 March 2011

\section{References}

1. Afari N, Buchwald D: Chronic fatigue syndrome: a review. Am J Psychiatry 2003, 160:221-236

2. Prins JB, van der Meer JWM, Bleijenberg G: Chronic fatigue syndrome. Lancet 2006, 367:346-355.

3. Wessely S, Chalder T, Hirsch S, Wallace P, Wright D: The prevalence and morbidity of chronic fatigue and chronic fatigue syndrome: a prospective primary care study. Am J Public Health 1997, 87:1449-1455.

4. Joyce J, Rabe-Hesketh $S$, Wessely S: Reviewing the reviews: the example of chronic fatigue syndrome. JAMA 1998, 280(3):264-266.

5. Luthra A, Wessely S: Unloading the trunk: neurasthenia, CFS and race. Soc Sci Med 2004, 58:2363-2369.

6. Edmonds M, McGuire H, Price J: Exercise therapy for chronic fatigue syndrome. Cochrane Database Syst Rev 2004, 3:CD003200.

7. Patel V, Kirkwood B, Weiss H, Pednekar S, Fernandes J, Pereira B, Upadhye M, Mabey D: Chronic fatigue in developing countries: population based survey of women in India. BMJ 2005, 330:1190.

8. Steele L, Dobbins JG, Fukuda K, Reyes M, Randall B, Koppelman M, Reeves WC: The epidemiology of chronic fatigue in San Francisco. Am J Med 1998, 105:83S-90S.

9. Shefer A, Dobbins JG, Fukuda K, Steele L, Koo D, Nisenbaum R, Rutherford GW: Fatiguing illness among employees in three large state office buildings, California, 1993: was there an outbreak? J Psychiatr Res 1997, 31:31-43.

10. Jason LA, Richman JA, Rademaker AW, Jordan KM, Plioplys AV, Taylor RR, McCready W, Huang CF, Plioplys S: A community-based study of chronic fatigue syndrome. Arch Intern Med 1999, 159:2129-2137.

11. Buchwald D, Umali P, Umali J, Kith P, Pearlman T, Komaroff AL: Chronic fatigue and the chronic fatigue syndrome: prevalence in a Pacific Northwest health care system. Ann Intern Med 1995, 123:81-88.

12. Prins JB, Bos E, Huibers MJ, Servaes P, van der Werf SP, van der Meer JW, Bleijenberg G: Social support and the persistence of complaints in chronic fatigue syndrome. Psychother Psychosom 2004, 73:174-182.

13. van der Werf SP, de Vree B, van der Meer JW, Bleijenberg G: The relations among body consciousness, somatic symptom report, and information processing speed in chronic fatigue syndrome. Neuropsychiatry Neuropsychol Behav Neurol 2002, 15:2-9.

14. Kelly KS, Soderlund K, Albert C, McGarrahan AG: Social support and chronic fatigue syndrome. Health Commun 1999, 11:21-34.

15. Stansfeld SA, Fuhrer R, Shipley MJ: Types of social support as predictors of psychiatric morbidity in a cohort of British Civil Servants (Whitehall II Study). Psychol Med 1998, 28:881-892.

16. Karlsen S, Nazroo JY: Relation between racial discrimination, social class, and health among ethnic minority groups. Am J Public Health 2002, 92:624-631. 
17. Krieger N: Refiguring "race": epidemiology, racialized biology, and biological expressions of race relations. Int J Health Serv 2000, 30:211-216.

18. Mustillo S, Krieger N, Gunderson EP, Sidney S, McCreath H, Kiefe Cl: Selfreported experiences of racial discrimination and Black-White differences in preterm and low-birthweight deliveries: the CARDIA Study. Am J Public Health 2004, 94:2125-2131.

19. Nazroo J, Jackson J, Karlsen S, Torres M: The Black diaspora and health inequalities in the US and England: does where you go and how you get there make a difference? Sociol Health IIIn 2007, 29:811-830.

20. Centers for Disease Control and Prevention: Chronic fatigue syndrome: the revised case definition. [http://www.cdc.gov/cfs/general/case_definition/ index.html].

21. Reeves WC, Lloyd A, Vernon SD, Klimas N, Jason LA, Bleijenberg G, Evengard B, White PD, Nisenbaum R, Unger ER, International Chronic Fatigue Syndrome Study Group: Identification of ambiguities in the 1994 chronic fatigue syndrome research case definition and recommendations for resolution. BMC Health Serv Res 2003, 3:25.

22. Viner RM, Clark C, Taylor SJ, Bhui K, Klineberg E, Head J, Booy R, Stansfeld SA: Longitudinal risk factors for persistent fatigue in adolescents. Arch Pediatr Adolesc Med 2008, 162:469-475.

23. Harvey SB, Wadsworth M, Wessely S, Hotopf M: Etiology of chronic fatigue syndrome: testing popular hypotheses using a national birth cohort study. Psychosom Med 2008, 70:488-495.

24. Viner R, Hotopf M: Childhood predictors of self reported chronic fatigue syndrome/myalgic encephalomyelitis in adults: national birth cohort study. BMJ 2004, 329:941.

25. Clark LV, White PD: The role of deconditioning and therapeutic exercise in chronic fatigue syndrome (CFS). J Ment Health 2005, 14:237-252.

26. Erens B, Primatesta P: Health Survey for England 1998: Cardiovascular Disease London: The Stationery Office; 1999

27. Erens B, Primatesta P, Prior G: Health Survey for England: the Health of Minority Ethnic Groups London: The Stationery Office; 2001.

28. Sproston K, Nazroo J: Ethnic Minority Psychiatric Illness Rates in the Community (EMPIRIC): quantitative report London: Her Majesty's Stationery Office; 2002.

29. Weich S, Nazroo J, Sproston K, McManus S, Blanchard M, Erens B, Karlsen S, King M, Lloyd K, Stansfeld S, Tyrer P: Common mental disorders and ethnicity in England: the EMPIRIC study. Psychol Med 2004, 34:1543-1551.

30. Chalder T, Berelowitz G, Pawlikowska T, Watts L, Wessely S, Wright D, Wallace EP: Development of a fatigue scale. J Psychosom Res 1993, 37:147-153.

31. Stansfeld S, Marmot M: Deriving a survey measure of social support: the reliability and validity of the Close Persons Questionnaire. Soc Sci Med 1992, 35:1027-1035.

32. Lewis G, Pelosi AJ, Araya R, Dunn G: Measuring psychiatric disorder in the community: a standardized assessment for use by lay interviewers. Psychol Med 1992, 22:465-486.

33. Pearlin LI, Schooler C: The structure of coping. J Health Soc Behav 1978, 19:2-21.

34. Bhui K, Stansfeld S, McKenzie K, Karlsen S, Nazroo J, Weich S: Racial/ethnic discrimination and common mental disorders among workers: findings from the EMPIRIC Study of Ethnic Minority Groups in the United Kingdom. Am J Public Health 2005, 95:496-501.

35. Killoran AJ, Fentem PH, Caspersen C: Moving on: International Perspectives on Promoting Physical Activity London: Health Education Authority; 1995.

36. Department of Health: Saving Lives: Our Healthier Nation White Paper and Reducing Health Inequalities: An Action Report London: Department of Health; 1999.

37. Dinos S, Khoshaba B, Ashby D, White PD, Nazroo J, Wessely S, Bhui KS: A systematic review of chronic fatigue, its syndromes and ethnicity: prevalence, severity, co-morbidity and coping. Int J Epidemiol 2009, 38:1554-1570.

38. Clark MR, Katon W, Russo J, Kith P, Sintay M, Buchwald D: Chronic fatigue: risk factors for symptom persistence in a $2 \frac{1}{2}$-year follow-up study. Am J Med 1995, 98:187-195.

39. Lin JM, Brimmer DJ, Maloney EM, Nyarko E, Belue R, Reeves WC: Further validation of the Multidimensional Fatigue Inventory in a US adult population sample. Popul Health Metr 2009, 7:18.

40. Hamilton WT, Gallagher AM, Thomas JM, White PD: Risk markers for both chronic fatigue and irritable bowel syndromes: a prospective casecontrol study in primary care. Psychol Med 2009, 39:1913-1921.
41. White PD, Thomas JM, Kangro HO, Bruce-Jones WDA, Amess J, Crawford DH, Grover SA, Clare AW: Predictions and associations of fatigue syndromes and mood disorders that occur after infectious mononucleosis. Lancet 2001, 358:1946-1954.

42. Ware NC, Kleinman A: Culture and somatic experience: The social course of illness in neurasthenia and chronic fatigue syndrome. Psychosom Med 1992, 54:546-560.

\section{Pre-publication history}

The pre-publication history for this paper can be accessed here: http://www.biomedcentral.com/1741-7015/9/26/prepub

doi:10.1186/1741-7015-9-26

Cite this article as: Bhui et al:: Chronic fatigue syndrome in an ethnically diverse population: the influence of psychosocial adversity and physical inactivity. BMC Medicine 2011 9:26.

\section{Submit your next manuscript to BioMed Central and take full advantage of:}

- Convenient online submission

- Thorough peer review

- No space constraints or color figure charges

- Immediate publication on acceptance

- Inclusion in PubMed, CAS, Scopus and Google Scholar

- Research which is freely available for redistribution 